[McDonald, L., \& Melchior, L. (2008). Investing in Transfer of Learning: Dancing the Talk. New Zealand Annual Review of Education, 17, 73-90]

\section{Investing in Transfer of Learning: Dancing the Talk}

\author{
LEX MCDONALD AND LIZ MELCHIOR
}

\section{Abstract:}

The tertiary education sector in New Zealand is changing, with more and more emphasis being placed upon outcomes and the relationship that universities have with their stake-holders. There is a danger that the complexities of change may over-shadow some key issues in the transformation. This article highlights the importance of one of the keys to accomplishing a meaningful relationship with the stakeholders - the development of teaching strategies that ensure transfer of learning occurs. A case study of a professional education programme in dance is outlined as an example of how planning for the impact of outcomes can be accomplished.

$\mathrm{T}$

tertiary education scene in New Zealand is currently undergoing considerable change. The education and training needs of the students and the needs of the stakeholders and community are being prioritised, and increased emphasis is being placed upon ensuring that the knowledge, skills, and attitudes associated with tertiary study are transferred (Tertiary Education Commission, 2007). One means of accomplishing this is the utilisation of the technology of transfer of learning, and yet this is viewed as problematic in the tertiary setting (Benander \& Lightner, 2005; Halpern \& Hakel, 2003), despite its significance for professional and vocational preparation (Cree \& Macaulay, 2000). In this article, a case study of the effective use of transfer technology in a tertiary education professional development programme is outlined.

\section{Changing Tertiary Education}

Since the beginning of the new millennium, the government has implemented legislative, administrative and strategic changes in the

\section{Lex McDonald and Liz Melchior}

tertiary sector, and in 2006 it foreshadowed an intention to implement a major shift in the alignment of funding, quality and monitoring in the tertiary sector (Cabinet Policy Committee, 2006). This change essentially entailed the linking of tertiary funding to performance and achievement with the demonstration of an evidence base. Previously, funding simply rewarded participation in tertiary education, but these latest policies link funding to the needs of the students and the local and national communities. It is a complex set of changes involving the incorporation of government priorities via monitoring by the Tertiary Education Commission, and it is bringing about a changing culture with significant impacts upon planning, business and community relations with the university, and student management systems. An important aspect of the policy is that tertiary education organisations are having to develop investment plans to meet stakeholders' needs, as well as documenting and demonstrating outcomes. The transfer of learning technology provides a vehicle for this to occur.

The interest in providing a tertiary education that is relevant, responsive to community needs, and performance-linked is not new. Over ten years ago, Skilbeck (1997) noted that it had been debated for some time. Indeed, it is related to the contemporary debate about the role and nature of education and training in tertiary settings in society, but regardless of this, there has been an increasing demand for education and training to be more focussed. This has come about because of a range of defining developments (e.g., technological change and knowledge expansion, changed paradigms of learning, demand for relevance and return-on-investment) (Leberman, McDonald \& Doyle, 2006). As McDonald (2005) noted, these increased demands for accountability and focussed outcomes have become key features of tertiary education, because the vocational needs of the students were previously not often well met. Some critics have called for different arrangements for tertiary education. For example, Gallagher (2000) commented positively on the rise of "corporate universities" that emphasised such things as the inter-disciplinary skills of problem-solving and teamwork. The OECD (2000) stressed the importance of "apprenticeship universities" whereby teaching models that accentuated tacit procedural knowledge, rather than declarative knowledge, were emphasised. An explicit defining of the implications of this for the teaching staff is required, otherwise the complexities of change can overshadow some of the key issues. Fundamental to this demonstration of learning outcomes, as it relates to the needs of the 
stakeholders, is an understanding and utilisation of the concept of transfer of learning, because it provides educators with the processes and skills to facilitate student learning across a variety of contexts.

\section{Transfer in Tertiary Settings}

According to Detterman (1993), transfer of learning refers to the degree to which the learned behaviour "is repeated in a new situation" (p. 4). In cognitive psychology - a field that is currently contributing significantly to the transfer area - many useful approaches have been developed. For example, cognitive apprenticeships (Anderson, 1983), goal setting (Morin, 1999), action plans (Werner \& DeSimone, 2006) and the notion of "preparation for future learning" (Bransford \& Schwartz, 1999) are recognised as valuable procedures. Nevertheless, other theoretical approaches have also produced ideas. For example, the behavioural approach has identified the significance of contextual factors (Ormrod, 1998), Broad and Newstrom's (1992) management approach highlighted the significance of a matrix "role $x$ time" perspective, whilst the work of Analoui (1993) emphasised the contribution of the socio-cultural milieu. In acknowledging these different perspectives, Leberman et al. (2006) promoted the value of a more systematic and consistent approach to transfer when working with tertiary students.

Leberman et al. note that many tertiary education staff are aware that learning should transfer, but few have the necessary skills and application knowledge to implement the processes strategically. In some respects this is surprising, because transfer is the core of all learning. However, there are probably two important reasons why tertiary educators lack this knowledge and the accompanying skills - most do not have substantive training in teaching methodology or knowledge of educational theory, and secondly, the concept and processes of transfer of learning are very complex, bewildering and open to debate. In the literature, however, there is a growing recognition that adult educational psychology requires very careful consideration and development (see Smith, 1999). This, along with other literature on transfer (Cree \& Macaulay, 2000; Haskell, 2001; Perkins \& Salomon, 1992; Schunk, 2004), acknowledges the central position of transfer in adult learning. This of course has implications for the tertiary education sector and other adult education contexts. Indeed, over 35 years ago, Knowles (1970) acknowledged that one of the key principles of adult learning was the application of that learning to the real world. What was implied was the need for the learner to apply the relevant learning in a meaningful manner. The notion of transfer of learning clearly is not new, but has in the past 15-20 years undergone a resurgence of interest.

Importantly, a distinction needs to be made between transfer of learning and professional development. These are related concepts, but do differ in terms of intent. Effective professional development is an educationally-focused process, and is concerned with achieving outcomes (Guskey, 2000), but often centred on an immediate context. As cited in Timperley, Wilson, Barr and Fung (2007, p. viii), Earl states that it encompasses "the kinds of learning that help teachers develop and grow in ways that will serve all their students well." On the other hand, transfer of learning is a concept oriented towards outcomes, initially located in the psychological and subsequently the management literature, dependent certainly upon a process, but relating to its application in a range of contexts. Essentially effective professional development centres on the "how", and transfer of learning on the "what", but the former is dependent upon the latter if the desired outcomes are to be achieved.

In the last ten years of the twentieth century there has been growing recognition of the importance of transfer in higher education (Assiter, 1995; Humphreys, Greenan \& Mcllveen, 1997; Kemp \& Seagraves, 1995; Murphy, 1997). The work of Leberman et al. (2006) addressed the issues of how tertiary educators and trainers could promote transfer from the perspective of participants. Generally however, considerable work still needs to be undertaken to advance ideas and link tertiary education to a performance orientation. Most commentators would agree that what is now needed is considerably more research, conceptual development and identification of strategic approaches to facilitate transfer in specific settings.

Although not specifically focussing on the tertiary sector, Haskell (2001) has developed perhaps one of the more potentially constructive approaches, because of its inclusive theoretical orientation and his repudiation of a "smorgasbord-strategies" approach to teaching for transfer - he considers learning and transfer to be inextricably intertwined, and yet notes that what we already know about learning (to transfer), is often overlooked. He believes there are no "quick fixes" for transfer, but on the basis of extensive educational and other discipline research, has developed an integrative framework with a set of guiding principles for all of those involved in the teaching business. 
Systematic research validating the specifics of his approach for particular contexts is required, however. Following Haskell's (2001) approach, the framework outlined in Table 1 gives a range of strategies and suggestions that could be useful for many students in tertiary settings, with important implications for trainers/lecturers and other stakeholders.

Table 1 Principles of transfer in the tertiary setting*

\section{PRINCIPLES OF TRANSFER: IMPLICATIONS FOR THE \\ LEARNING ENVIRONMENT}

1. Acquire extensive knowledge base and expertise in the subject area

2. Develop knowledge base in peripheral and unrelated subject areas to draw analogies, consider similarities, and examine differences

3. Understand the background, context and important historical factors in relation to the content/skill area to be transferred

4. Be highly motivated and disposed to transfer at all times - develop a "spirit of transfer"

5. Develop an understanding about transfer, its significance and the skills to transfer

6. Develop higher level thinking skills that facilitate transfer

7. Nurture support for transfer to occur via development of a "transfer culture"

8. Develop theoretical knowledge of the area under consideration, as it is interdependent with transfer and provides a measure of what to transfer

9. Utilise practice and drill activities to consolidate the learning in preparation for transfer

10. Allow time for the learning and subsequent transfer to incubate

11. Use the experiences of other people who demonstrate the transfer spirit

* This table is adapted from Haskell, 2001.

These principles relate not only to the learner but also to the lecturer, as modelling and facilitation of the processes are necessary. The first principle emphasises that a large knowledge base encourages thinking, reasoning and discrimination - all prerequisites of transfer. Knowing the subject, the key concepts and theoretical issues, the controversies, how the subject can be applied and "stories" associated with it, are all essential sets of information for the student, and help the lecturer negotiate understanding. Conversely, knowledge in seemingly unrelated areas (principle two) is useful also, because it can be a source of analogies, similarities and differences - approaches that are invaluable in learning and teaching strategies (Marzano, 2003; Perkins \& Salomon, 1992). To further consolidate the learning of the topic, the history of that content area needs to be understood, for the reason that it helps in gaining knowledge of the present. It identifies the area of study; gives its origin, highlights and present features; avoids a "reinventing of the wheel"; and helps with course readings (third principle).

The fourth principle relates to the development of a "spirit of transfer", a concept implying personal and motivational commitment to transfer. For example, the work of Bereiter (1995) emphasises the importance of the learner's disposition toward transfer. An individual who is disposed to transfer typically engages in deep learning and demonstrates persistence, confidence and locus of control with an absence of anxiety and fear of failure. Related to this is the importance of understanding transfer and how to use transfer strategies (fifth principle) as well as the capacity to utilise higher-level thinking skills (sixth principle). The key players must know and understand what transfer is and how to employ appropriate strategies. Reference to the seminal work of Baldwin and Ford (1988) and the subsequent advances have been useful in facilitating understanding of transfer. These developments have essentially emphasised the roles of the learner, lecturer/workshop leader and supporting colleagues/context and the use of strategies before, during and after the learning event (Broad \& Newstrom, 1992; Broad, 2005). One of the important qualities of the learner is the capability to engage in higher-level thinking following encoding of the material. There are of course a range of strategies that can be utilised in the tertiary sector that can promote such thinking Bloom's taxonomy, problem-based learning, case method, cooperative learning strategies, graphic representations are but a few examples (see, for example, Nilson, 2003). These are metacognitive approaches that facilitate learning, promote retention and enable transfer to occur more readily.

Haskell's seventh principle identifies the importance of transfer culture (support) as an important dimension that aids transfer. What is implied is that transfer is enhanced when it is considered as a sociocultural and collective process (Analoui, 1993). For example, the effective 
educator/trainer initiates support networks as far as possible, the learner seeks support to implement ideas, and the work-based manager recognises the importance of collegial support in implementing such ideas (Broad \& Newstrom, 1992). Within a tertiary setting it may not be possible to arrange for external support, but preparing learners to harness this in their future work contexts can be planned.

A detailed theoretical knowledge of the area under study (eighth principle) emphasises the importance of declarative knowledge. Procedural and strategic knowledge have significant roles to play in tertiary education, but unless declarative knowledge is interwoven with sound theoretical knowledge, transfer is unlikely to occur. Furthermore, a learner's misconceptions can be identified when theory is considered, and this can be used to generate corrective feedback and thereby ensure positive transfer. Drill and practice activities (ninth principle) give emphasis to the importance of the procedural and strategic knowledge, as these activities emphasise active learning. With reference to training and professional development programmes, Joyce and Showers (2002) have identified coaching as a particularly potent strategy for transfer of procedural knowledge in a teaching sequence of knowledge presentation, demonstration and modelling, practice, peer coaching and ongoing feedback. This is a very similar approach to that developed by Salas and Cannon-Bowers (2000).

Allowing time for the learning and transfer to occur has increasingly become an important consideration (tenth principle). Transfer may not occur immediately, but given time it can incubate and develop - the scholarly work of Bransford and Schwartz (1999) is useful here. They argue that assisting the learner to locate ways of preparing for the future use of the new information is an enabling process, and should be the priority ahead of the direct transfer of knowledge and skills. They believe that exactly how the student will learn more in the future, make use of resources, gain support for the use of the ideas and demonstrate adaptive expertise are important considerations in a tertiary education programme. Haskell's last principle, the use of models, is concerned with locating and using individuals who have modelled the transfer spirit and have transitioned effectively into their work context. Such models can provide additional data on how best to transfer ideas and skills. Observing others, listening to stories and reading about transfer are some of the effective means of sharing such successes. Accordingly, the value of models displaying and outlining the use of their knowledge and skills in the real world has considerable value.
The framework in Table 1 thus provides a basic guide to the educator/trainer on how to promote transfer of learning in a tertiary setting. Haskell (2001) notes that, apart from these key principles, it is also important to identify the level and kind of transfer (i.e., the degree of similarity of contexts, the type of knowledge being transferred and the specific category of transfer) so that impact in the new context occurs. As indicated earlier, transfer is complex - but, as the following case study demonstrates, if careful planning is undertaken, it can be achieved.

\section{A Teacher Professional Development Case Study in Transfer}

In this case study, consideration is given to one type of tertiary education - a professional development programme for teachers. Although it may not reflect the traditional university mode of teaching and learning, it has implications for it, and could act as a model for other tertiary education programmes. It engaged mature adult learners in a school setting, and many of the transfer processes discussed above were incorporated into a strategic action plan. This programme was based around ideas from a number of sources (Beals, Hipkins, Cameron \& Watson, 2003; Broad \& Newstrom, 1992; Haskell, 2001; Hill, Hawk \& Taylor, 2002; Joyce \& Showers, 2000; Leberman et al., 2006; Salas \& Cannon-Bowers, 2000). The design of the programme centred on improving the outcomes for teachers, and it was considered that this would occur when the programme:

- was based upon a quality professional development programme that was characterised by a negotiation with individual teachers interested in the context of their own classroom;

- had the support of others; and

- was designed to meet the teachers' and students' needs.

This programme was initiated when the principal of an urban state primary school requested whole-school, in-depth teacher professional development in dance and visual arts over a two-year period. The facilitator was approached to provide a training programme that would promote teacher confidence and equip teachers with the necessary skills and knowledge to implement effective dance in the classrooms. The idea was that a multi-level approach (Kozlowski \& Salas, 1997) was being sought whereby the facilitator would transfer knowledge, skills and attitudes to the two lead teachers, who in turn would transfer the 
outcomes to others in the school. A distinction was made between the individual, team and organisational levels of transfer.

\section{The dance programme background}

A very experienced dance educator who had extensive experience as a classroom teacher, and in the past ten years had worked as a pre- and in-service teacher educator in dance, supported this professional development programme. She had also undertaken research investigating the impact of dance education on teaching practices. The programme, based upon an acknowledgement that change in teacher behaviour was not simple, required the facilitator to have considerable understanding of the transfer process. Furthermore, there was an understanding that to sustain the change it was more strategic and effective in the long-term if two key strategies were implemented. First, it was decided to work intensively with two teachers who displayed certain characteristics - they were motivated to learn and "own" the new developments, had a "let's try it" disposition, were committed to making change in practice and were prepared to plan for this to occur. They demonstrated a spirit of transfer. Although the operationalisation of this desire required time, it was beneficial because ongoing involvement with the key teachers helped to develop specific content and pedagogical knowledge that could then be used to develop other staff members' capabilities in dance. The second strategy related to support. Continued support from the facilitator ensured sustained progress and a shared vision. In addition, "buy in" from the staff and "visible" support from the principal were crucial for transfer of the learning.

\section{The programme: Before phase}

Before the professional development, considerable work to set the conditions for, and foster transfer of, the learning was undertaken. The focus for the programme was discussed at the initial meeting between the dance facilitator and the senior management team of the school. It centred on the principal's concerns that dance was not being taught effectively in the school and there was no sense of programme progress or planning continuity. The identified goal was to implement a quality dance programme whereby the students in the school progressively developed skills, attitudes and understandings.

The next step was to consult the staff about their specific needs for dance education. So that the lead teachers could met the needs of their colleagues, the facilitator used recent research on teaching and learning in the arts (Bresler, 1996; Buck, 2004; Eisner, 2002) to generate discussion and curiosity about theory and content. Using a jig-saw cooperative learning strategy (Kagan, 1994), the teachers identified their current practice, desired goals and needed resources. Fullan and Hargreaves (1996) and Stoll (1999) agree that collegial commitment to in-depth professional development increases the likelihood of transfer, with students and the community reaping the benefits.

If teachers are to be able to improve practice they need to be able to take risks, make mistakes, and engage in honest self-reflection. This requires a culture where relationships bind them together in a supportive, enquiring community. (Fullan \& Hargreaves cited in Hill, Hawk \& Taylor, 2002, p. 2)

A questionnaire was administered to all the teachers to access the teachers' prior knowledge and experiences, and perceived confidence and competence to teach the arts. This informal questionnaire ("Dance Professional Development Ladder") surveyed current skills and goals, and identified the skills and goals regarded as desirable for effectiveness as a dance educator. The results indicated a general lack of confidence to teach dance, with a corresponding lack of skill development. However, all acknowledged the value of dance in the curriculum and the potential for enhanced student engagement and achievement.

The next stage was the design of the professional development programme for the two lead teachers. The facilitator decided that learning would be accomplished via an experiential learning cycle (Kolb, 1984) that emphasised experience, reflection, thought, and action. Curriculum content and pedagogical knowledge would be developed side-by-side through interaction between the facilitator, lead teachers and staff. Modelling, observation, feedback, critical reflection and goal setting were the key activities at this stage - a synthesis of ideas previously developed by Melchior (2005). Learning would be regarded as an on-going process rather than a single event, with teacher release time being made available for the practice of new skills, discussion of new ideas, feedback and critical reflection (Jones \& Lowe cited in Yost, 2002).

To begin the process, the facilitator gathered baseline data from the two lead teachers via classroom observations, semi-structured interviews and self-appraisal procedures. At this stage support from the principal was crucial and this came in the form of encouraging comments, progress enquiries and provision of release time. 
Following consultations with the school staff, an action plan was developed, specifying the goal for the overall staff development, including:

- specific dance content and pedagogical knowledge that would improve teachers' competence and confidence to teach dance (Ministry of Education, 2000);

- idea that dance would be taught as an integral part of the classroom programme;

- planning that would result in a coherent and systematic progression of learning for all the teachers; and

- links with dance across the curriculum.

This groundwork, undertaken prior to the actual training events, was crucial and positioned the professional development as an important phase in the culture of the school.

\section{The programme: During phase}

It was during this phase that the facilitator worked intensively with the two lead teachers to develop their skills in dance. The programme itself was based on the premise that it was important to create a safe, supportive environment for learning, where participants felt included, valued and motivated. To facilitate this, four supporting conditions (Wlodkowski, 1999) for the two lead teachers were established. These conditions involved:

1. Establishing of inclusion: group discussion in which learners exchanged experiences, ideas, expectations and concerns;

2. Developing of positive attitudes: co-constructing learning goals that were relevant and achievable, so that teachers felt a sense of progress;

3. Enhancing of meaning: critical questioning and reflective thinking about teaching and learning and the value of dance in the curriculum; and

4. Engendering competence: self-assessment through reflective journals and evaluative statements concerning what they had learnt about dance in the curriculum; this also provided a record of how their attitudes were changing.

The teacher's journal documented and reflected upon the process from a personal and professional perspective. These data consisted of visual diaries (the students' pictures of their dance progress), video and photographs, teacher observation, teacher written feedback to students and student feedback to each other about achievements and goals. The facilitator encouraged the teachers to identify their individual strengths and interests and develop strategies to teach the dance. One teacher used her knowledge of literacy to facilitate skill development, and the other teacher used her own culture as a teaching resource. Not only did these teachers develop confidence to teach dance, but it also helped them to express opinions about their new repertoire of skills. As one of the teachers noted, "I've become more confident to organize dance and talk about it to the rest of the staff, because I really love it and I'm so excited." They improved their teaching by sharing ideas, discussing the accomplishments of their students and reflecting critically upon their work. Although the facilitator helped the teachers to learn the basic skills of dance, much of the learning occurred between the two lead teachers themselves who gave feedback and encouragement to each other; they were able to use to advantage their prior knowledge about their students and how they learned.

\section{The programme: After phase}

The lead teachers not only achieved their goal of effectively incorporating dance into their classroom programmes, but also developed their dance content and pedagogical knowledge to a level that made them valuable resource personnel for the other staff members. Significant changes in the pre-and post-survey results on the "Dance Professional Development Ladder" were noted, which provided a signal for the facilitator to withdraw. Accordingly, although the professional development programme formally concluded at the end of 2007, the facilitator maintained contact with the lead teachers. Essentially however, they were now confident to plan and teach dance without recourse to the facilitator, and were able to offer support initially to their syndicate members, and then to other staff. They have since developed a long term plan for dance with specified references to Ministry of Education resources and ideas for cross-curricular links. Teachers are now reporting to parents/caregivers on student achievement in dance, and have shared student work in a variety of contexts, both inside and outside the school.

With support and encouragement from the facilitator, the two teachers attended a teacher refresher course, presented a workshop, sharing the process and examples of their students' dance with other 
teachers. The principal continued to support the teachers and provided finance for them to attend the conference. He has subsequently paid for other teachers to attend dance education workshops. Significantly, the principal and staff were now taking responsibility to promote their own learning and were demonstrating high levels of motivation to continue to develop the dance programme as an important component of the school culture.

\section{Conclusion}

Significant outcomes in implementing the dance programme in this school were achieved. The two lead teachers (followed by the other staff members) became confident to plan and teach dance. They have developed a long-term plan with the staff, encouraging them progressively to teach dance throughout the school. Pre- and post-data, although self-report perceptions, indicated growth in confidence, planning, and implementation. The growing leadership capacity of the two lead teachers was noted by the principal.

There were a number of reasons why this professional development exercise was so successful. The facilitator carefully developed the programme and strategically arranged events so that transfer opportunities were maximized. The two lead teachers had positive dispositions - they were motivated and innovative and worked steadfastly to gain confidence. Their enthusiasm spread to the other teachers. The principal's support and commitment was a crucial component of the transfer process. He demonstrated a personal interest, ensuring that the programme was given priority and adequate resources for its implementation. In addition to this, he shared information about dance with parents and caregivers in school newsletters. Quotes from Eisner (2001) relating to the value of the arts in an education programme were relayed to the community. Furthermore, parents and caregivers have been regularly invited to view students' dance work and art displays and this has supported the teachers' development. The role undertaken by the principal highlights the role of key personnel (e.g., managers, line supervisors) as significant agents for implementation of change and impact of programmes (Broad \& Newstrom, 1992; Hill, Hawk \& Taylor, 2002; Melchior, 2006).

Tertiary education is changing. Not only has there been a re-thinking of the traditional modes of delivery, but increasingly there have been demands for a relevant community-referenced education that emphasises outcomes related to the contributions learners can make to a changing society. Regardless of the debates about the utility of tertiary education, it is important to recognise that transfer of learning is a central concept because it provides the bridge for all learning to become meaningful and of value. What is needed is a strategic approach to the application of the fundamentals of learning. This article has identified a number of key factors relating to tertiary education and transfer - in particular the importance of the dispositional qualities of the learners (and hence the importance of student motivation), the impact that an experienced and enthused lecturer can have on the learners, and the need to engineer and prepare for support (in real time and/or in the future). Tertiary education outcomes can have increased validity if the technology of transfer of learning is undertaken in this way.

\section{References}

Analoui, F. (1993). Training and transfer of learning. Aldershot, UK: Avebury.

Anderson, J. R. (1983). The architecture of cognition. Cambridge, MA: Harvard University Press.

Assiter, A. (1995). Transferable skills in higher education. London: Kogan Page.

Baldwin, T. T., \& Ford, J. K. (1988). Transfer of training: A review and directions for future research. Personnel Psychology, 41, 63-105.

Beals, F., Hipkins, R., Cameron, M., \& Watson. S. (2003). An evaluation of professional development to support the arts in the New Zealand curriculum. Wellington: Ministry of Education.

Benander, R., \& Lightner, R. (2005). Promoting transfer of learning: Connecting general education courses. Journal of General Education, 54(3), 199-208.

Bereiter, C. (1995). A dispositional view of transfer. In A. McKeough \& L. J. Marini (Eds.), Teaching for transfer: Fostering generalisation in learning (pp. 21-34). Mahwah, NJ: Erlbaum.

Bransford, J. D., \& Schwartz, D. (1999). Rethinking transfer: A simple proposal with multiple implications. In A. Iran-Nejad \& P. D. Pearson (Eds.), Review of Research in Education (Vol. 24, pp. 61-100). Washington, DC: American Educational Research Association.

Bresler, L. (1996). Traditions and change across the arts: Case studies of arts education. International Journal of Music Education, 27, 24-35. 
Broad, M. L. (2005). Beyond transfer of training: Engaging Systems to Improve Performance. San Francisco: Pfeiffer.

Broad, M. L., \& Newstrom, J. W. (1992). Transfer of training: Action packed strategies to ensure high payoff from training investments. Reading, MA: Addison-Wesley.

Buck. R. (2003). Teachers and dance in the classroom "So, do I need my tutu?" Unpublished PhD thesis, University of Otago, Dunedin.

Cabinet Policy Committee. (2006). Tertiary education reforms: The next steps. Accessed January 15, 2008, from: <www.tec.govt.nz/upload/download/ cabinet-paper-tertiary-education-reforms-the-next-steps.pdf $>$.

Cree, V., \& Macaulay, C. (Eds). (2001). Transfer of learning in professional and vocational education. London: Routledge.

Detterman, D. K. (1993). The case for the prosecution: Transfer as epiphenomenon. In D. K. Detterman \& R. J. Sternberg (Eds.), Transfer on trial: Intelligence, cognition, and instruction (pp. 1-24). Norwood, NJ: Ablex.

Eisner, E. W. (2002). The arts and the creation of mind. New Haven \& London: Yale University Press.

Fullan, M., \& Hargraves, A. (1996). What's worth fighting for in your school? New York: Teachers College Press.

Gallagher, M. (2000, June). Corporate universities, higher education and the future: Emerging policy issues. Paper presented at the Corporate University Week 2000, Department of Education, Science and Training, Sydney, Australia.

Guskey, T. (2000). Evaluating professional development. Thousand Oaks, CA: Corwin Press.

Halpern, D., \& Hakel, M. (2003). Applying the science of learning to the university and beyond. Change, 35(4), 36-41.

Haskell, R. E. (2001). Transfer of learning. Cognition, instruction and reasoning. San Diego, CA: Academic Press.

Hill, J., Hawk, K., \& Taylor, K. (2002). Professional development: What makes it work? set: Research Information for Teachers, 2, 12-15.

Humphreys, P., Greenan, K., \& Mcllveen, H. (1997). Developing work-based transferable skills in a university environment. Journal of European Industrial Training 21(2), 63-69.
Joyce, B., \& Showers, B. (2002). Student achievement through staff development. Alexandria, VA: Association for Supervision and Curriculum Development (ASCD).

Kemp, I., \& Seagraves, L. (1995). Transferable skills - Can higher education deliver? Studies in Higher Education, 20(3), 315-328.

Knowles, M. S. (1970). The modern practice of adult education: From pedagogy to andragogy. New York: Cambridge.

Kozlowski, S. W., \& Salas, E. (1997). A multilevel organisational systems approach for the implementation and transfer of training. In J. K. Ford, S. W. Kozlowski, K. Kraiger, E. Salas, \& M. S. Teachout (Eds.), Improving training effectiveness in work organizations (pp. 247-290). Mahwah, NJ: Lawrence Erlbaum Associates.

Leberman, S., McDonald, L., Doyle, S. (2006). The transfer of learning: Participants' perspectives of adult education and training. Aldershot, UK: Gower.

McDonald, L. (2005). Teacher education, training and experience: Knowing what, how, when, why and with. New Zealand Annual Review of Education, 14, 131-151.

Melchior, E. (2006). If you can walk you can dance. How generalist primary teachers develop confidence and competence to teach dance. Unpublished MEd thesis, Victoria University of Wellington.

Morin, L. (1999) Mental practice and goal setting as transfer of training strategies: Their influence on self-efficacy and task performance of team leaders in an organisational setting. Dissertation abstracts International, Section A: Humanities and social sciences, 60(1-A):0187.

Murphy, E. (1997, February). From university to work: Developing transferable skills. The Proceedings of the 6th Annual Teaching Learning Forum, "Learning through teaching", Murdoch University, Western Australia.

Nilson, L. B. (2003). Teaching at its best: A research-based resource for college instructors. Bolton, MA: Anker Publishing Company.

Organisation for Economic Co-operation and Development. (2000). From initial education to working life: Making transitions work. Paris: OECD.

Ormrod, J. E. (1998). Educational psychology. Developing learners. Upper Saddle River, NJ: Prentice Hall.

Ormrod, J. E. (2004). Human learning. Upper Saddle River, NJ: Pearson. 
Perkins, D. N., \& Salomon, G. (1992). Transfer of learning. International Encyclopaedia of Education (2nd ed.). Oxford, UK: Pergamon Press.

Salas, E., \& Cannon-Bowers, J. A. (2000). Design training systematically. In E. A. Locke (Ed.), The Blackwell handbook of principles of organizational behaviour (pp. 43-59). Malden, MA: Blackwell.

Schunk, D. (2004). Learning theories: An educational perspective. Upper Saddle River, NJ: Pearson.

Skilbeck, M. (1997). Higher education in a changing environment. Regional, national and trans-national issues. Tertiary Education and Management, 3(2), 101-111.

Smith, M. C. (1999). Adult educational psychology: Diverse perspectives from an emerging field. Introductory comments. Paper presented at the annual meeting of the American Educational Research Association, Montreal, Canada.

Stoll, L. (1999). Realising our potential: Understanding and developing capacity for lasting improvement. School Effectiveness and School Improvement, 10, 1-30.

Tertiary Education Commission. (2007). Investment guidance 2008-2010. Wellington: TEC.

Timperley, H., Wilson, A., Barrar, H., \& Fung, I. (2007). Teacher professional learning and development: Best evidence synthesis iteration. Wellington: Ministry of Education.

Werner, J. M., \& DeSimone, R. L. (2006). Human resource development. Cincinnati, $\mathrm{OH}$ : Thomson/South-Western.

Wlodkowski, R. (1999). Enhancing adult motivation to learn. San Francisco: Jossey-Bass.

Yost, R. (2002). I think I can: Mentoring as a means of enhancing teacher efficacy. Clearing House, 75(4), 195-97.

\section{The authors}

Lex McDonald is a senior lecturer in the School of Education Studies, and Director of Post-Graduate Studies, Faculty of Education, Victoria University of Wellington. He has a background in teaching and in the practice of psychology. Research interests include adult education, transfer of training, instructional psychology, inclusive education and effective teaching and learning strategies. Lex has a number of publications in the area of training with a particular interest in training in international contexts.
Liz Melchior is a lecturer in the School of Primary and Secondary Education, Victoria University of Wellington. She has a background in primary teaching. Research interests include dance pedagogy, including the assistance of teachers in implementing inclusive dance programmes in the classroom. She works in pre- and in-service teacher education programmes, and is a strong advocate for the arts in education. 